\title{
EREBEA
}

Revista de Humanidades y Ciencias Sociales

Núm. 10 (2020), pp. 31-52

ISSN: 0214-0691

http://dx.doi.org/10.33776/erebea.v10i0.4959

\section{Risk Behaviors among Young People: The Role of Developmental Assets}

\author{
Sahar Issa \\ Kronstad District Psychiatric Center, Norway \\ Mali Frøshaug Rossland \\ Regional Office for Children, Youth and Family Affairs, Eastern Norway \\ Nora Wiium \\ Faculty of Psychology, University of Bergen, Norway
}

AbSTRACT

Youth risk behaviors have both personal and societal consequences and can also have grave economic cost if not addressed effectively. Positive Youth Development (PYD) as a theoretical framework proposes that facilitating developmental assets (i.e., internal and external assets, such as positive values and social support) among young people would lead to positive outcomes as well as a possible reduction in negative outcomes. The empirical evidence supporting these assertions mostly come from studies involving American samples. In the present study, we examine whether the experience of more developmental assets is associated with less engagement in three risk behaviors: drunkenness, violence and crime among 591 Norwegian students $(55 \%$ girls $)$, mean age $16.70(\mathrm{SD}=.90)$. Our results indicate that while several significant correlations were observed between developmental assets and risk behaviors, only two internal assets: positive values and social competence, and two external assets: support and boundaries and expectations were significant predictors of

\section{RESUMEN}

Las conductas de riesgo en los jóvenes tienen consecuencias tanto personales como sociales y también pueden tener un grave coste económico si no se abordan de manera eficaz. El marco teórico del Desarrollo Positivo Juvenil (DPJ) propone que fomentar los activos del desarrollo (internos y externos, como pueden ser los valores positivos y el apoyo social) entre los jóvenes conduciría a resultados positivos, así como a una posible reducción de los resultados negativos. La evidencia empírica que respalda estas afirmaciones proviene principalmente de estudios con muestras estadounidenses. En el presente estudio, examinamos si la presencia de más activos de desarrollo se asocia con una menor participación en tres conductas de riesgo: embriaguez, violencia y delincuencia, entre 591 estudiantes noruegos (55\% niñas), con una edad promedio de 16,70 (DT = $0,90)$. Nuestros resultados indicaron que si bien se observaron varias correlaciones significativas entre los activos del desarrollo y las conductas de riesgo, sólo dos activos internos (valores positivos y competencia 
a risk behavior in multivariate regression analysis. Although these positive findings have some implications for intervention and youth policy, more research is needed to ascertain the short- and long-term protective effects of the developmental assets on risk behaviors among Norwegian youth.

KeYwORDS

Positive youth development; developmental assets; risk behaviors; Norway. social) y dos activos externos (apoyo social, y límites y expectativas) fueron predictores significativos de conducta de riesgo en el análisis de regresión multivariante. Aunque estos hallazgos tienen algunas implicaciones para la intervención y la política con la población juvenil, se necesita más investigación para determinar los efectos protectores a corto y largo plazo de los activos del desarrollo sobre las conductas de riesgo entre los jóvenes noruegos.

\section{Palabras Clave}

Desarrollo positivo juvenil; activos de desarrollo; conductas de riesgo; Noruega.

\section{Author Note:}

This research was funded by the Faculty of Psychology, University of Bergen, Norway. We would like to thank our youth participants in Norway for their engagement in the present study. 
Adolescence is one of the key developmental periods of the life course, a period that is characterized by significant biological, social, and cognitive changes. These large and rapid changes increase the possibility for both positive and negative developmental outcomes. Although many youth do not participate in risk behaviors, several others engaged in high risk behaviors that can cause both acute, and chronic health challenges (Balocchini, Chiamenti \& Lamborghini, 2013). The identity formation processes that young people go through during adolescence is not only associated with the strive for independence, but it can also be a period of experimentation and engagement in risk behaviors (Spano, 2004). As engagement in risk behaviors is a leading cause of mortality in youth (Balocchini et al., 2013), researchers and professionals are keen to understand both predictors and protective factors.

Research on risk behaviors suggests that predictors are located on both individual and contextual levels (Muchimba, 2019; Wiium, \& Wold, 2009). Among young people, key factors of risk behaviors include personal factors (e.g., male gender, older adolescents, low academic success and positive attitudes; Boričić, Simić, \& Erić, 2015; Wiium, \& Wold, 2009), family factors (e.g., insufficient, passive or lack of paternity/maternity, parent-child relationship; Moradi, Fathali Lavasani, \& Dejman, 2019; Shek, Zhu, Dou, \& Chai, 2020) and community-level factors (e.g., school-connectedness, school disciplinary measures; Muchimba, 2019; Wiium \& Wold, 2011). Thus, to understand the development of risk behaviors in youth, both individual and contextual factors need to be studied. While several of these factors, especially those related to demographics are fixed and unchangeable, others, such as parent-child relationship and school-connectedness can be modified.

Earlier methods of reducing risk behaviors focused primarily on youth weaknesses and problem behaviors. This deficit approach led to problem-focused prevention strategies, programs, and guidelines (Donovan \& Jessor, 1985; Elias $\&$ Weissberg, 2000). In recent decades, a new approach, which focuses on the positive aspects of youth development has emerged. The focus has been on promoting developmental assets that can act as a buffer or facilitator of healthy development rather than guidelines to reduce problem behaviors (Leffert et al., 1998; Scales, 1999). A widely used framework for understanding positive development of young people is the developmental asset model proposed by 
Benson (1990, 2007) and the Search Institute in Minneapolis, United States. Consistent with the asset model, youth development is enabled by the access to developmental assets (e.g., positive values and social support) in youth contexts. In the present study, we examine the protective role of developmental assets as indicated by youth strengths and contextual resources in risk behaviors, such as drunkenness, violence and crime among Norwegian youth.

\section{Positive Youth Development and Developmental Assets}

Positive Youth Development (PYD) is a perspective in developmental psychology that contrasts with prevention science. The perspective focuses on youth as potential resources, rather than problems that need to be prevented (Silbereisen \& Lerner, 2007). PYD is anchored in relational developmental system theories that describe youth development as a function of the interaction between individuals and their contexts, such as family, peers, school, workplace, neighborhood and community (Benson, 2007; Lerner et al., 2005; Overton, 2010). The assumption is that all young people have strengths that when aligned with the resources in their contexts will create an adaptive developmental process where both youth and their contexts benefit. Thus, this reciprocal and beneficial relationship is expected to facilitate thriving and civic engagement among young people (Lerner et al., 2005).

Within the PYD framework, youth strengths and contextual resources have typically been referred to as developmental assets (Benson, 2007). In collaboration with the Search Institute, Peter Benson presented 40 developmental assets, which he put under two major categories: internal and external assets. Internal assets, which represent individual and psychological characteristics, were further grouped into four sub-categories: commitment to learning (e.g., achievement motivation, and school engagement), positive values (e.g., integrity and responsibility), social competencies (e.g., planning and decision-making, and resistance skills) and positive identity (e.g., self-esteem and sense of purpose). External assets represent the contextual and relational features of socializing system and also comprised four sub-categories: support (e.g., family support and caring school climate), empowerment (e.g., how the community values youth and community's perception of youth as resources), boundaries and expectations (e.g., family boundaries and significant others' expectations of young people), and constructive use of time (e.g., in creative activities and youth programs) (Benson, 2007). Together, internal and external assets signify skills, resources and opportunities that can be found in five different youth contexts: personal, social, family, school, and community. Earlier studies with samples from diverse ethnic groups and countries have not only confirmed the psychometric properties of the scales that have been used to assess the assets but also the facilitating role of the assets in youth development (Scales, 2011; Scales, Roehlkepartain, \& Shramko, 2017). 


\section{Development Assets and Risk Behaviors}

Although the PYD theoretical assumption highlights the role of the developmental assets in the promotion of positive youth outcomes and healthy development, the protective role of the assets on risk behaviours has also been observed, empirically. For example, Scales (1999) studied the relationship between Benson's (2007) 40 developmental assets, risk behavior patterns and thriving in a sample of almost 100,000 6th-12th grade youth in 213 different communities across the United States and found that youth who reported 31-40 developmental assets were less likely to show risk behavior patterns relative to those who reported 0-10 assets. Specifically, youth who experienced the highest assets were less likely to report abuse of alcohol or the experience of violence compared to those who experienced low (0-10) or average (11-20) assets. Moreover, Scales (1999) observed that at every level of developmental deficits, such as experiencing violence, spending too much time alone without supervision or being abused physically, youth who reported high assets were risk-free despite their deficits. Further, youth in vulnerable conditions appear to benefit more from high levels of assets even in increasing vulnerable conditions. Thus, despite the experience of some deficits, youth with high level of assets were able to completely avoid risk behaviors.

In another American study involving 30,916 students in grades 8-12, Murphey, Lamonda, Carney, and Duncan (2004) observed that the number of assets (e.g., academic success, and communication with parents about school) reported by the students was negatively associated with each of the seven risk behaviors that were also assessed (e.g., binge drinking and marijuana use for the past 30 days). The findings were independent of demographic factors, such as gender, grade and ethnicity. Moreover, an independent assessment of the assets revealed that each of them was a significant predictor of the risk behaviors, although academic success (measured as grades in school) was found to be the strongest predictor of most of the risk behaviors.

Chatterjee and colleagues (2018) explored the moderating effect of internal assets on the association between adverse experiences in childhood and early initiation of marijuana and alcohol use. Their sample comprised 79, 339 9th and 11th graders, attending public schools in Minnesota, United States. Adverse childhood experiences included experiences of any abuse and or any household dysfunction, while positive identity and social competence were assessed as internal assets. The authors found that internal assets moderated the influence of experiencing both abuse and household dysfunction on early initiation of marijuana and alcohol use in female participants. Thus, for girls who reported lower internal assets scores, the association between adverse childhood experiences and marijuana or alcohol initiation was stronger relative to girls who reported high scores on internal assets. 
In a study with 510 students who self-identified as American Indian, Greene, Eitle, and Eitle (2018) investigated the protective role of personal, family, school, and community assets in risky sexual behaviors, such as early sexual debut, number of sexual partners and frequency of condom use. They found that selfcontrol (personal asset), family support and parent communication (family assets) as well as school attachment and non-deviant friends (school assets) and caring adults (community asset) were protective of several of the risky sexual behaviors. Moreover, the authors found that cumulative assets as a variable was an important predictor of the sexual behaviors, where a standard deviation increase in cumulative assets was associated with a $46 \%$ decrease in the odds of engaging in early sexual debut.

Thus, from earlier studies, the empirical evidence regarding the protective role of the developmental assets or resources, whether as individual or in cumulative form, has been supported. Although some of these studies have been conducted outside the United States, most studies have involved American contexts and samples. In the present study, we extend the scope of research context as well as the generalizability of Benson's (2007) assets by studying the protective role of these assets in risk behaviors, such as drunkenness, violence and crime activities in a Norwegian youth sample.

\section{The Present Study}

In Norway, the alcohol culture is relatively liberal, and the acceptance level for intoxication and consumption is significantly higher compared to countries in southern-Europe, for example (Nordlund \& Østhus, 2012). Although a decline has been seen over the last decade, there are still many, including young people who have unhealthy alcohol consumption lifestyles. For example, in a recent study by Bakken (2019), 3-4 \% of Norwegian early adolescents, and $80 \%$ of students, ages 16-19 reported that they had gotten drunk in the last 12 months. Among youth, alcohol consumption usually occurs in settings related to socialization and flirting, while for some, engaging in the behavior marks a kind of transition from childhood to adolescence (Bakken, 2019).

Violence and criminal offences are also reported to some extent among young people in Norway. In a study conducted to assess these behaviors, 13\% reported that they had threatened someone with violence, while $34 \%$ of boys, and $11 \%$ of the girls reported that they had been in a physical fight (Bakken, 2018). Statistics from the Police department for the first half of 2019 showed that the incidence of physical violence has increased significantly from 2015 (Straffeloven, 2019). The increase among boys is most evident, as they are to a greater extent found to engage in various forms of violence relative to girls (Bakken, 2018).

Norwegian societies like many others want a healthy and positive development for their youth. Subsequently, both local initiatives and national youth policies 
addressing areas, such as education, active citizenship, participation and civil engagement have been put together to enable youth to participate in economic, social, and political development. In the present study, we examine a sample of Norwegian youth's access to developmental assets and how these resources are related to their engagement in risk behaviors. As observed in several studies, we hypothesize that youth who score high on developmental assets will also report less drunkenness, violence and crime.

\section{Method}

\section{PARTICIPANTS}

The current study collected data from 591 upper secondary school students attending a public school in Bergen, Norway as part of a cross-national research project (Wiium \& Dimitrova, 2019). The age range of participants was 15-19 years (Mage $=16.70, S D=.90)$. In terms of gender distribution, $55 \%$ were girls. Furthermore, about $56 \%$ reported having a father with post-secondary education, while $67 \%$ had a mother with similar level of education.

\section{MEASURES}

Demographics. Participants were asked to provide information about their gender (i.e., boy or girl), age and parents' education (i.e., no education, primary school, secondary school, technical or vocational school and university education). In the analysis, the five response categories of parents' education were treated as two categories: lower than post-secondary and post-secondary.

Developmental assets. Participants were asked to indicate the extent to which they had experienced Benson's (2007) four internal asset categories (i.e., commitment to learning, positive values, social competencies and positive identity) and four external asset categories (i.e., support, empowerment, boundaries and expectations and constructive us of time). Items measuring internal assets were related for example, to learning new things, helping other people, planning ahead and making good choices, as well as feeling good about one's future. For external assets, items were for example related to asking parents for advice, being given useful roles and responsibilities in youth settings, having friends who are good role models and being involved in creative activities, such as music and theatre. Responses were on a 4-point Likert scale ranging from 1 (Not at all or rarely) to 4 (Extremely or almost always), with high scores indicating more experiences of the assets.

While Benson (2007) proposes 40 assets, in the Developmental Assets Profile (Search Institute, 2020), assets that address multiple contexts (e.g., home and school) have been expanded such that each context is addressed separately. In the present study, 51 items reflecting the 40 assets were examined. Besides constructive use of time, Cronbach's alphas of the internal assets and external assets ranged from .73 to .86 , indicating adequate internal consistencies. 
Constructive use of time had a Cronbach's alpha of .44. The Cronbach's alpha values are similar to those $(\alpha=.60 \mathrm{~s}-.80 \mathrm{~s})$ reported by Scales, Benson, Leffert, $\&$ Blyth (2000). For data analysis, composite variables that reflect the number of assets reported for each of the eight asset category were created by recoding the 4-point Likert scale into a binary one (i.e., responses 1 and 2 as asset absent; 3 and 4 as asset present).

Risk-behaviors. Participants reported on three risk behaviors: drunkenness, 1 item related to whether they have been drunk one or more times in the last 30 days; violence, 3 items, asking for example, whether they had physically harmed anyone one or more times in the last 12 months; crime, 2 items, where participants indicated for example, whether they have been involved in shoplifting one or more times in the last 12 months. Response options were 0 (No) and 1 (Yes). Composite variables were created for violence and crime so that for crime, for example, the scale ranged from 0 to 2, 0 (indicating no engagement in crime), 1 (engagement in one crime activity) and 2 (engagement in 2 crime activities).

\section{PROCEDURE}

The study was approved by the Regional Committee for Medical and Health Research Ethics (REK) in Norway, and the data collection was conducted in 2015. Prior to the survey, informed consent was obtained, first from the head of school and then from the participants who had been informed about the goals and procedure of the study. Upper secondary school students from one public school in Hordaland municipality that had recently been created out of 4 schools took part in the survey, with a response rate of $70 \%$. Data collection lasted for about 40 minutes during school hours. Participants had access to the questionnaire through the school's internal web system. The questionnaire was translated from English to Norwegian by Semantix Translations Norway AS, an organization that specializes in interpreting and translation services.

\section{STATISTICAL ANALYSIS}

Statistical Package for the Social Science (SPSS) version 25 was used for the data analyses. Chi-square analyses were conducted to examine the distribution of the three risk behaviors across the demographic variables: gender, age, and parents' education. Correlation analysis was performed to assess the extent to which the different study variables correlated with each other. Finally, regression analysis was undertaken to examine the influence of the developmental assets on drunkenness, violence, and crime in the Norwegian sample, while controlling for demographic variables. Pairwise deletion was used to account for missing data and the $\mathrm{p}$-value, $p<.05$ was used to assess statistical significance. 


\section{Results}

\section{CHI-SQUARE ANALYSIS of RISK BEHAVIORS ACROSS DEMOgRAPHIC VARIABLES}

Chi-square analysis did not show any significant difference in drunkenness across gender, father's, or mother's education. However, age difference was observed, $X 2(4, N=497)=54.604, p=.000$, where the proportion of drunkenness increased from $3.7 \%$ among 15 years to $21.3 \%$ among 16 years, and further to $39.6 \%$ among 17 years (Table 1 ). For violence, the only significant result was found for gender, $X 2(3, N=586)=9.727, p=.021$, where boys relative to girls reported the highest incidence of both one (51.4\%), two (72.7\%) and three $(85.7 \%)$ acts of violence (Table 1$)$. Furthermore, for crime, only significant age difference was observed, $X 2(8, N=531)=16.262, p=.039$, where 16-year-olds reported the highest incidence $(54.5 \%)$ of two crime activities and 19 -year-olds reported no crime (Table 1).

\section{CORRELATION ANALYSES OF STUDY VARIABLES}

Negative and statistically significant correlations were observed among the eight asset categories and three risk behaviors although they were weak (.10 .29) to moderate (.30 - .49) (Cohen, 1988). The highest significant correlation was found between support and violence $(r=-.32, p<.01)$, while the lowest was between positive values and violence $(r=-.09, p<.05)$. Rather unexpectedly, a positive and significant correlation was found between constructive use of time and crime, $(r=.09, p<.05)$, although the correlation was small (Table 2).

Several significant correlations were also found between the demographic variables (especially, gender and age), the asset categories and risk behaviors. Significant correlations between gender and the internal assets indicated that girls scored higher than boys on commitment to learning $(r=.14, p<.01)$, positive values $(r=.16, p<.01)$, and social competence $(r=.21, p<.01)$, while boys scored higher than girls on positive identity $(r=-.14, p<.01)$. For external assets, girls scored higher than boys on support $(r=.13, p<.01)$ as well as boundaries and expectation $(r=.14, p<.01)$. For risk behaviors, boys only reported more violence than girls $(r=-13, p<.01)$. Like gender, significant correlations were observed between age and several asset categories, where younger participants reported more positive values $(r=-.11, p<.05)$, support $(r=-.09, p<.05)$, boundaries and expectations $(r=-.15, p<.01)$ and constructive use of time $(r=-.11, p<.05)$. For risk behaviors, older participants reported more drunkenness $(r=.31, \mathrm{p}<.01)$, but less crime $(r=-.09, p<.05)$, relative to younger peers. The only significant correlation between parents' education and the asset categories as well as the risk behaviors was between mother's education and support $(r=.12, p<.01)$, where participants whose mothers had post-secondary education reported more assets compared to peers whose mother had lower than post-secondary education. 


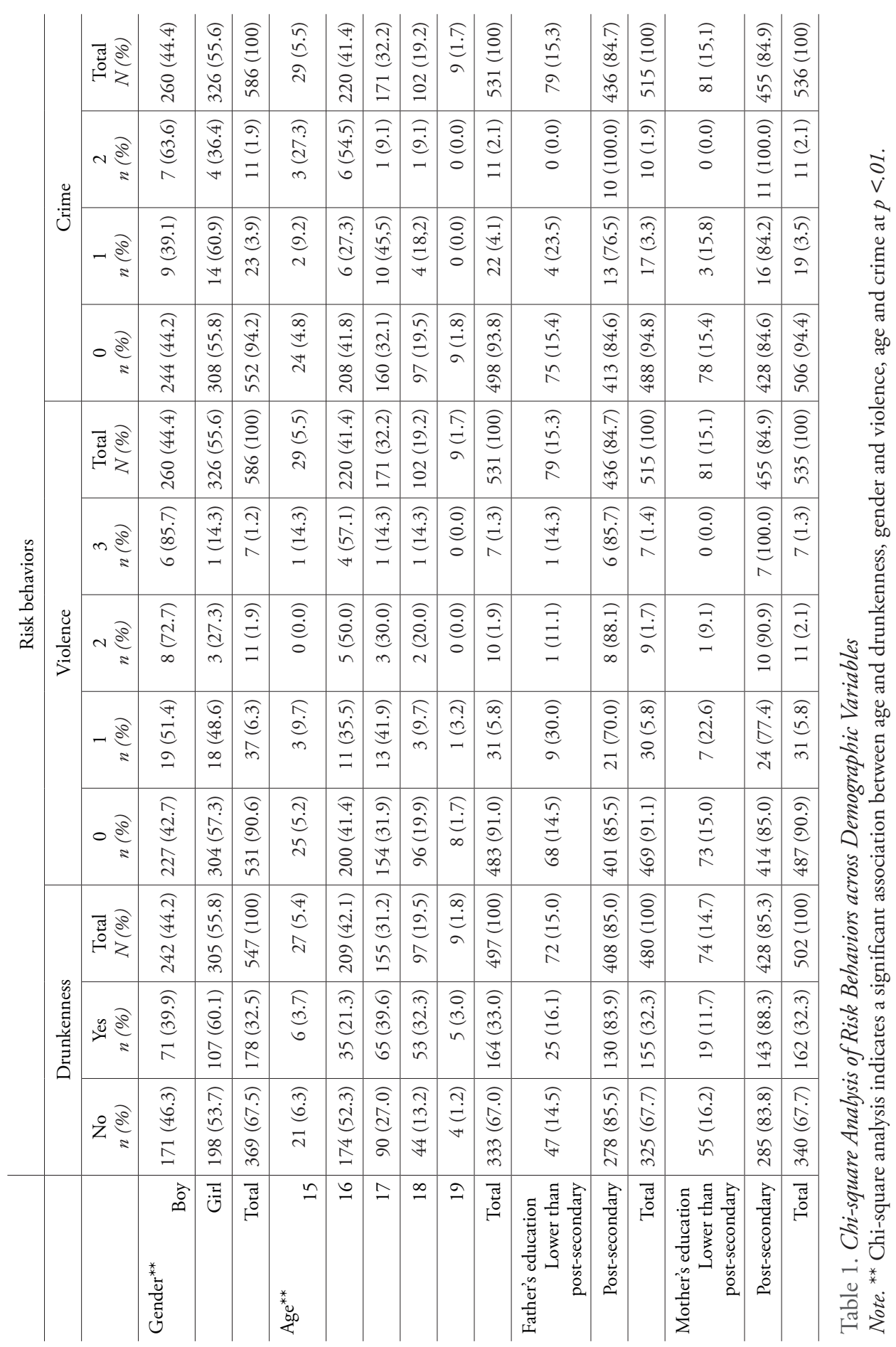




\begin{tabular}{|c|c|c|c|c|c|c|c|c|c|c|c|c|c|c|c|c|c|c|c|c|}
\hline 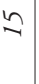 & $\tilde{o}_{i}^{\infty}$ & $\stackrel{0}{o}_{i}^{*}$ & $\tilde{o}_{i}^{2}$ & ?o & $\begin{array}{l}* \\
\stackrel{*}{0} \\
i\end{array}$ & $\Xi_{i}$ & $\stackrel{\stackrel{*}{*}}{\stackrel{*}{?}}$ & $\begin{array}{l}{ }_{0}^{*} \\
\stackrel{0}{0} \\
i\end{array}$ & 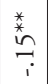 & $\stackrel{*}{\stackrel{*}{\stackrel{*}{*}}}$ & $\stackrel{*}{\stackrel{*}{*}} \underset{:}{\stackrel{1}{i}}$ & ồ & $\stackrel{*}{\stackrel{*}{*}}$ & 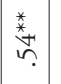 & & & $\tilde{o}$ & $\stackrel{\infty}{0}$ & $\stackrel{n}{n}$ & \\
\hline 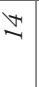 & $\stackrel{*}{\stackrel{*}{?}}$ & $\hat{n}_{i}$ & $\underset{i}{+}$ & ô. & $\begin{array}{l}\infty \\
\stackrel{i}{i} \\
\end{array}$ & $\underset{i}{*}$ & $\stackrel{*}{\stackrel{*}{*}} \underset{i}{\stackrel{1}{*}}$ & 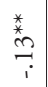 & $\stackrel{*}{*}$ & \begin{tabular}{l}
$*$ \\
\multirow{6}{*}{} \\
-1 \\
$i$
\end{tabular} & 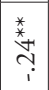 & ô. & 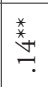 & & & & $\hat{o}$ & 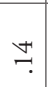 & $\stackrel{\infty}{+}$. & \\
\hline$\approx$ & 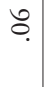 & $\stackrel{*}{*}$ & $\tilde{O}$ & ঃ & $\stackrel{*}{\stackrel{*}{\sim}} \underset{i}{\longrightarrow}$ & $\begin{array}{l}\underbrace{*}_{6} \\
\stackrel{*}{i} \\
:\end{array}$ & $\tilde{n}_{i}^{n}$ & $\vec{D}_{i}^{+}$ & $\Xi_{i}^{0}$ & ô. & $\stackrel{*}{*}$ & $\tilde{n}$ & & & & & $\stackrel{I}{\perp}$ & $\underset{\overbrace{}}{\tilde{g}}$ & †े & \\
\hline$\approx$ & $\tilde{\sigma}$ & $\stackrel{*}{=}$ & $\tilde{c}_{i}^{\infty}$ & oै & $\stackrel{*}{\underset{*}{*}}$ & $\stackrel{*}{*} \underset{\infty}{\rightarrow}$ & $\stackrel{*}{\stackrel{*}{上}}$ & 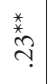 & 苦 & $\stackrel{*}{*}$ & $\begin{array}{l}\text { 苦 } \\
0 \\
\text { ? }\end{array}$ & & & & & & $\begin{array}{l}+ \\
\dot{0}\end{array}$ & $\stackrel{\Re}{\stackrel{r}{\sim}}$ & $\underset{-}{\stackrel{2}{0}}$ & \\
\hline$\succsim$ & $\stackrel{*}{*}$ & : & $\stackrel{+}{\circ}$ & $\stackrel{\infty}{0}$ & \begin{tabular}{l} 
悉 \\
\multirow{2}{*}{.}
\end{tabular} & $\stackrel{\text { * }}{\forall}$ & $\begin{array}{l}\stackrel{*}{*} \\
\stackrel{\infty}{\infty} \\
\stackrel{+}{+}\end{array}$ & ڤે & 悉 & 莡 & & & & & & & $\hat{o}$ & $\begin{array}{l}n \\
\infty \\
\sigma \\
\sigma\end{array}$ & $\stackrel{\Lambda}{\infty}$ & \\
\hline 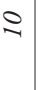 & ?. & $\tilde{o}_{i}$ & $\stackrel{n}{o}$ & 巳o & $\begin{array}{l}\text { 悉 } \\
\text { t. }\end{array}$ & 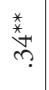 & 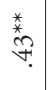 & $\stackrel{*}{n}$ & 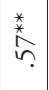 & & & & & & & & $\begin{array}{l}\text { o } \\
\dot{0}\end{array}$ & $\stackrel{m}{n}$ & તิ & ¿े \\
\hline$a$ & $\stackrel{*}{m}$ & ${ }_{0}^{*}{ }_{i}^{*}$ & $\tilde{o}$ & $\stackrel{*}{\stackrel{*}{\beth}}$ & 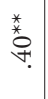 & $\stackrel{\text { * }}{\stackrel{n}{n}}$ & $\stackrel{*}{*} \stackrel{*}{n}$ & $\begin{array}{l}\text { 悉 } \\
\text { ! }\end{array}$ & & & & & & & & & $\hat{o}$ & $\begin{array}{l}\stackrel{+}{\infty} \\
\stackrel{\forall}{*}\end{array}$ & 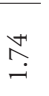 & 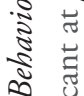 \\
\hline$\infty$ & $\begin{array}{l}\stackrel{*}{*} \\
\stackrel{*}{+} \\
i\end{array}$ & $\tilde{o}_{i}$ & $\tilde{o}$ & $\dot{\sigma}^{+}$ & 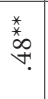 & $\begin{array}{l}* \\
\infty \\
\infty \\
n\end{array}$ & 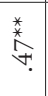 & & & & & & & & & & $\begin{array}{l}y^{\prime} \\
d^{\prime}\end{array}$ & $\begin{array}{l}\infty \\
\stackrel{i}{i}\end{array}$ & $\stackrel{\infty}{\stackrel{\infty}{-}}$ & 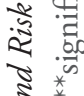 \\
\hline$\Lambda$ & $\stackrel{*}{*}$ & $\tilde{o}_{i}$ & $\sigma^{\prime}$ & $\vec{\sigma}_{i}$ & 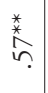 & 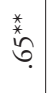 & & & & & & & & & & & $\hat{o}$ & $\stackrel{\curvearrowright}{\stackrel{\leftrightarrow}{n}}$ & $\stackrel{\vec{\sigma}}{-}$ & $\begin{array}{l}\ddot{6} \\
\dot{0} \\
\dot{y}\end{array}$ \\
\hline 6 & $\stackrel{*}{*}$ & $\stackrel{*}{=}$ & $\overbrace{}^{+}$ & $\overbrace{i}^{\infty}$ & $\stackrel{*}{*}$ & & & & & & & & & & & & $\hat{o}$ & $\begin{array}{l}\hat{n} \\
i n\end{array}$ & : & $\begin{array}{l}0 \\
0 \\
0 \\
0 \\
0 \\
0\end{array}$ \\
\hline n & $\stackrel{*}{*}$ & $\stackrel{\infty}{\infty}$ & $\&$ & $\tilde{o}_{i}$ & & & & & & & & & & & & & $\hat{o}$ & $\begin{array}{l}\vec{n} \\
i n\end{array}$ & $\stackrel{શ}{-}$ & בัँ \\
\hline$\forall$ & $\overrightarrow{0}_{i}$ & $\stackrel{*}{\stackrel{*}{*}} \underset{i}{\rightarrow}$ & $\begin{array}{l}\text { 悉 } \\
\text { t. }\end{array}$ & & & & & & & & & & & & & & $\overrightarrow{0}$ & $\infty$ & 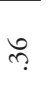 & \\
\hline$n$ & oै. & $\stackrel{*}{\stackrel{*}{*}}$ & & & & & & & & & & & & & & & $\overrightarrow{0}$ & 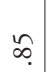 & $\stackrel{\overbrace{}}{\dddot{n}}$ & \\
\hline$\sim$ & $\tilde{\sigma}$ & & & & & & & & & & & & & & & & $\stackrel{\vec{n}}{\stackrel{n}{n}}$ & $\begin{array}{l}\stackrel{R}{0} \\
\stackrel{\sigma}{0}\end{array}$ & §. & ڤัँ \\
\hline 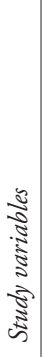 & 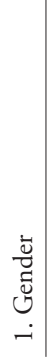 & 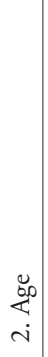 & 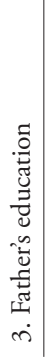 & 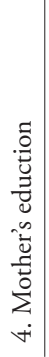 & 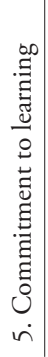 & 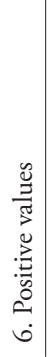 & 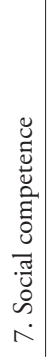 & 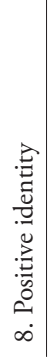 & $\mid \begin{array}{l}\vec{z} \\
0 \\
\hat{a} \\
\vec{z} \\
\tilde{\sigma} \\
\dot{\sigma}\end{array}$ & 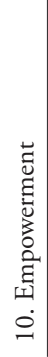 & 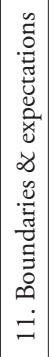 & 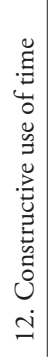 & 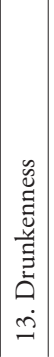 & 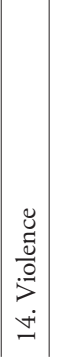 & 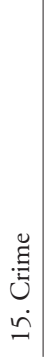 & 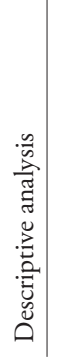 & 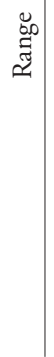 & $\stackrel{\Xi}{\Sigma}^{\Xi}$ & 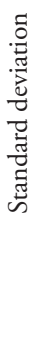 & 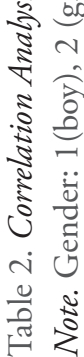 \\
\hline
\end{tabular}




\section{PREDICTING RISK BEHAVIORS: REGRESSION ANALYSES}

In regression analyses (logistic or linear), the influence of all eight asset categories was assessed on the three risk behaviors, separately, while controlling for the demographic variables. In logistic regression of drunkenness, positive values retained its significance, $(O R=0.72 ; 95 \% C I=0.60-0.87)$, while the external asset categories, empowerment $(O R=1.40 ; 95 \% C I=1.04-1.86)$ and constructive use of time $(O R=1.40 ; 95 \% C I=1.07-1.82)$ showed positive associations with drunkenness, as in correlation analysis. Significant odds ratios were also found for several of the demographic variables (Table 3).

Results from the linear regression of violence indicated social competence $(\beta=$ $-.19, p<.01)$, support $(\beta=-.17, p<.01)$, as well as boundaries and expectations $(\beta=-.17, p<.05)$ as significant predictors of the outcome, where participants who reported more of the assets were less likely to engage in violence. However, commitment to learning $(\beta=.12, p<.05)$ and constructive use of time $(\beta=.10, p$ $<.05$ ) had positive association with violence (Table 4). We do not find this positive association with commitment to learning in the correlation, and therefore consider it as due to a suppression effect. Suppression effect applies when the direction of an association between two variables is reserved after a third variable is introduced. This usually applies when the two independent variables are highly correlated. In the results, some of the developmental assets correlate quite highly with each other, but not higher than 0.80 , which is the most typical cut-off in multicollinearity tests (Vatcheva, Kee,s \& McCormick, 2016). None of the demographic variables was significant in this multivariate regression analysis of violence. On their own, the demographic variables explained $2.1 \%$ of the variance in violence $(R 2=.021)$, while the asset categories explained an additional $10 \%$ of the variance.

For crime, results from the linear regression only showed constructive use of time as a significant predictor, where participants who reported more of the assets were also more likely to commit crime $(\beta=.17, \mathrm{p}<.01)$. This association was also found in the correlation. Furthermore, although social competence correlated significantly with crime, the association was barely significant in the multivariate regression analysis $(\beta=-.11, \mathrm{p}=.099)$, and no demographic variable was significantly related to crime (Table 4 ).

\section{Discussion \\ MAIN FINDINGS}

Chi-square analysis of the association between the demographic factors and risk behaviors showed a significant association between age and drunkenness, where older participants more than younger peers engaged in the behavior. In contrast, younger participants reported more crime than older peers. Furthermore, boys reported higher incidence of violence relative to girls. Neither father's nor mother's education was associated with any of the risk behaviors. In correlation 
Risk Behaviors among Young People

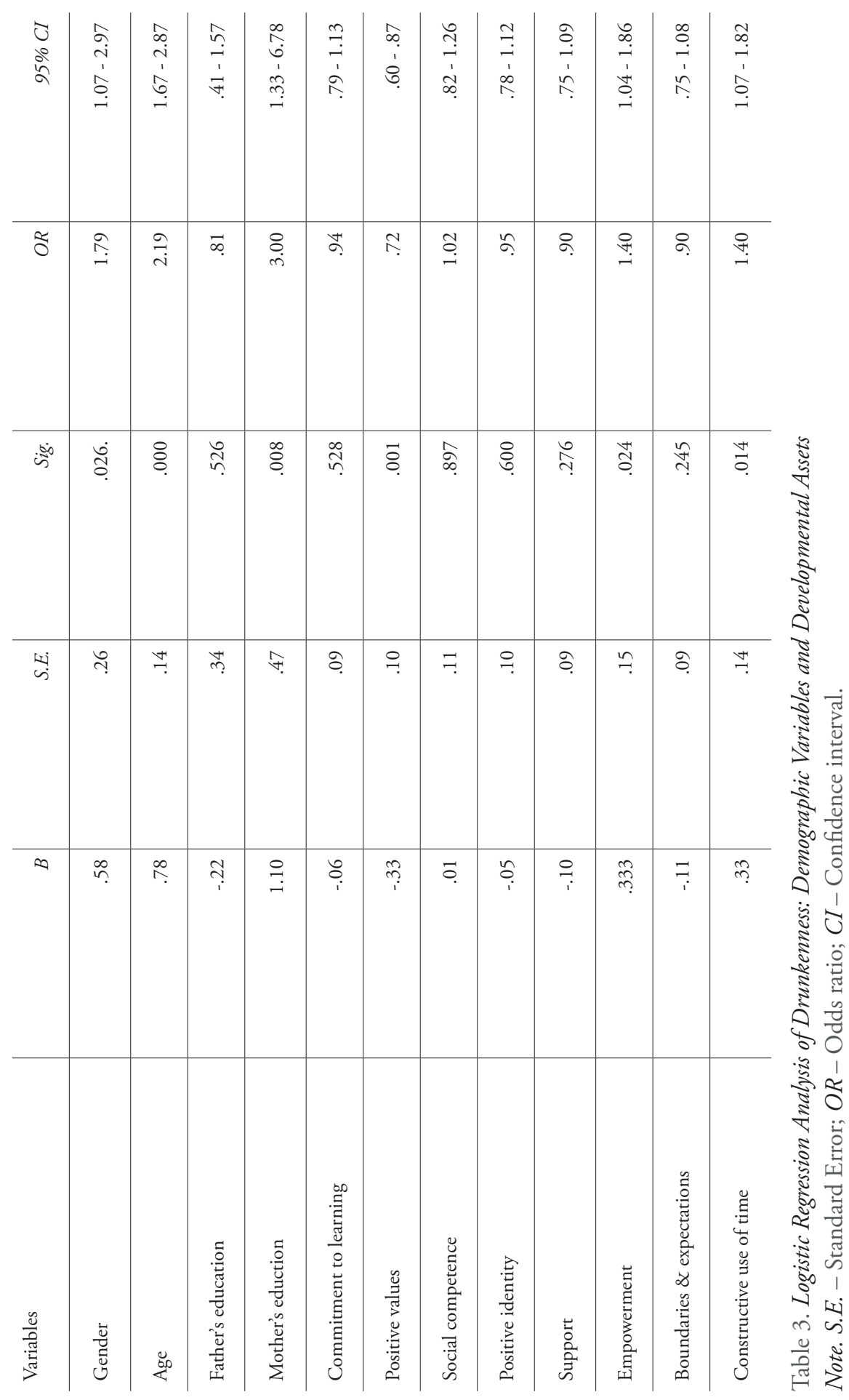




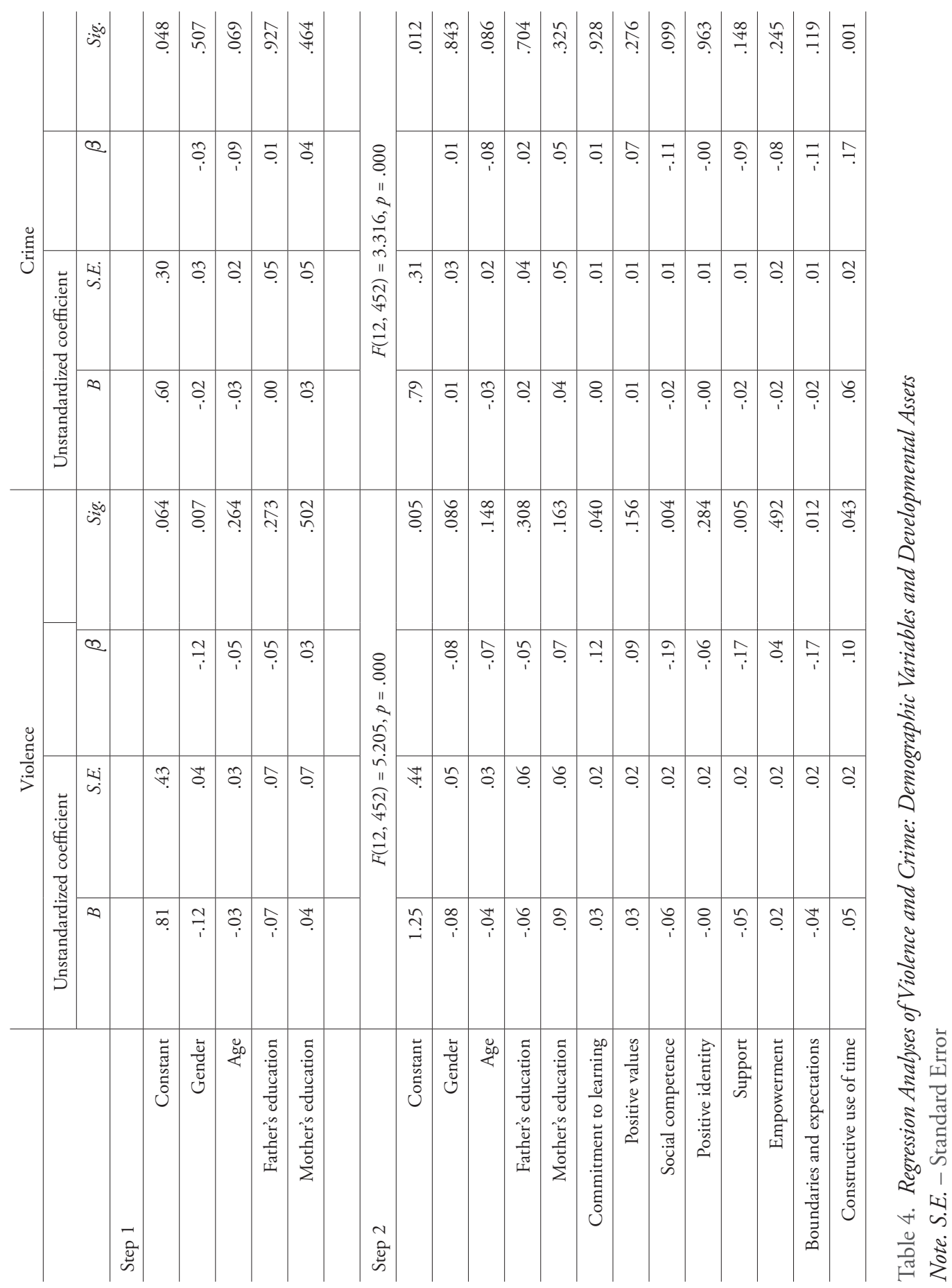


analysis, several expected correlations were observed between the asset categories and the risk behaviors, although the correlations were mostly weak to moderate.

In regression analysis, a negative association was observed between positive values and drunkenness. The result also showed a negative association between violence and three asset categories: social competence, support as well as boundaries and expectations in line with our anticipations. However, and rather expectedly, a positive association was observed in both correlation and regression analyses between empowerment and drunkenness, constructive use of time and drunkenness and between constructive use of time and crime. Moreover, a positive association was observed between commitment to learning and violence in regression analysis, a finding that was not observed in the correlation analysis, thus indicating a probable suppression effect.

\section{DEVELOPMENTAL ASSETS AND RISK BEHAVIORS}

Using the PYD framework, the present study investigated the hypothesis that youth who experience more developmental assets would be less likely to engage in risk behaviors. While findings from the correlation analysis appear to confirm the hypothesis for several of the asset categories, only two internal assets: positive values and social competences, and two external assets: support and boundaries and expectations were significant predictors of a risk behavior in the multivariate regression analysis. Thus, our hypothesis was only partially confirmed.

Not many of the asset categories were associated with drunkenness. Only the positive values asset category was a significant predictor. Thus, although as a developmental asset, this finding is supported by earlier studies, such as Scales (1999), which also found a protective effect of the developmental assets, the current finding was not supported by Chatterjee and colleagues (2018), who found a protective effect of positive identity and social competence on alcohol and marijuana use among youth in demanding life situations. One possibility for the current findings could be that the significant influence of positive values was reinforced by the other asset categories as they were found to correlate with each other in our study. Another possibility could be that participants' responses to being drunk one or more times during the last 30 days was actually not considered as a risk behavior among upper secondary school students in a liberal alcohol Norwegian culture. Thus, developmental assets may not necessarily act as a protector against drunkenness as the behavior may be socially acceptable in Norway.

Three asset categories: one internal asset category (social competence), and two external asset categories (support and boundaries and expectations) predicted violence. Thus, both individual and contextual level assets appear to be protective against violence in Norwegian youth. In the present study, the behavior is measured as enacting physical harms and engaging in fights. Social competence, which reflected for example, being able to resolve conflicts and accepting people who 
are different from one's self could help young people refrain from such violence. Moreover, having parents or guardians who are good at talking about things and neighbors who care (i.e., support) as well as a family that provide clear rules and friends who set good examples (i.e., boundaries and expectations) tend to highlight the significant role of family and peers in risk behaviors during adolescence. In their study, Fosco, Stormshak, Dishion, \& Winter (2012) found that good family ties and parental monitoring protected against substance abuse and antisocial behavior, while Leffert and colleagues (1998) found positive peer influence to be an important predictor of less involvement in antisocial and violent behaviors.

Findings from the multivariate regression analysis did not indicate any significant association between the asset categories and crime, in the anticipated direction, although there was an indication that social competence could be a significant predictor $(p=.099)$. Constructive use of time (an external asset category) was though, found to be positively associated with crime, a finding that was also observed in correlation analysis. This finding contradicts our hypothesis of a negative association between developmental assets and participation in risk behaviors, but it does not differ significantly from previous findings. Gottfredson, Gerstenblith, Soulé, Womer, and Lu (2004) examined the effect of participation in an after-school program on youth delinquent behavior in Maryland, United States, and found that for older students (grades 6-8), participation in the program that offered academic assistance, social skills training, and recreational activities, did not reduce delinquent behavior. Moreover, Spruit, van Vugt, van der Put and van der Stouwe (2016) did not find a negative association between participation in sport (one of the items that measured constructive use of time) and youth crime in their meta-analysis.

Still, it is strange to think that participation in creative activities could be promoting the very behaviors that need to be prevented. Although participation in activities, such as sports clubs, leisure clubs, and religious congregations are considered constructive, they can also be arenas where youth come together with other negative peer groups, in addition to the fact that these groups may not always be led or monitored by responsible adults. In the absence of responsible adults and proper supervision, places where youth meet for recreation could be a breeding ground for risk behaviors.

\section{LimitATIONS AND ReCOMMENDATIONS}

The present study has some limitations that need to be considered in the interpretation of the findings. First, there is the limitation in relation to the measurement of some of the study variables. For example, drunkenness was assessed as being drunk one or more times in the last 30 days. For young Norwegians and perhaps the Norwegian society, this may not necessarily be considered as a risk behavior because of the liberal alcohol culture in Norway. It is 
therefore not surprising that very few associations were observed between the asset categories and drunkenness even in correlation analysis, compared to violence and crime. Thus, in future studies, other behaviors, such as drunk driving could be rather investigated. Still on measurement issues, constructive use of time had a low reliability value and did not appear to effectively capture the constructive activities that youth in Norway are involved in. This is not an isolated case as similar findings have been reported, for example, for youth in Turkey and Italy as well (Wiium, Dost-Gözkan, \& Kosic, 2018). Future research should therefore explore creative activities that can be unique for youth in their specific settings.

The present finding could also be replicated in a more representative sample that includes more than upper secondary school students, and preferably with longitudinal design, as the present study was based on cross-sectional data collected from a convenience youth sample. Moreover, the self-report responses of participants can be a limitation of the study. Some of the risk behaviors studied are considered antisocial and, to some extent, go against social norms and legal legislation. The responses of young people could therefore be affected by social desirability. At the same time, the assured anonymity at the beginning of data collection provided participants with the opportunity to answer honestly, without experiencing any consequences.

\section{Implications for Research, Policy and Practice}

The present study indicates that both internal and external developmental assets are protective against youth risk behaviors and that the role of these resources may differ across countries and cultures. This latter argument is based on comparisons that have been made with earlier studies of the assets in the American context. Thus, the current study provides a relevant framework for further research on the developmental assets and their role in preventing risk behaviors among young people in Norway and other Scandinavian countries. The influence of demographic factors, such as gender, age and parents' education will be relevant to explore as some of them were significantly related to the developmental assets and risk behaviors. With risk behaviors, other relevant forms of violence, such as digital and psychological violence (i.e., using electronic devices to intentionally frighten or hurt, verbal aggression, intimidation) that goes beyond what was studied can be investigated. With the rise of social media and continuous access to the internet, it is conceivable that much of the violence that young people are exercising, and experiencing, is taking place on social media platforms. By including these types of violence and other risk behaviors, one would be able to examine a broader picture of the link between developmental assets and risk behaviors.

Furthermore, the current findings lay an important foundation for youth policy. The protective role of the developmental assets in risk behaviors that was 
observed is important to note. Risk behaviors can be a major financial and social burden for society, and it will be of political interest to come up with strategies that can prevent or reduce the behavior, while promoting the course of young people, as this will yield socio-economic benefits. Investments could be made in effective youth programs that will enable youth to develop to their full potential.

For practical implications, youth contexts, such as home, school and local communities can take advantage of the fact that putting in efforts to nurture developmental assets for young people would be one way of preventing them from engaging in risk behaviors. Moreover, teaming up with other youth contexts in resource-building activities would be an effective way to address risk behaviors in young people as well as liberal social and cultural norms on risk behaviors, such as alcohol consumption.

\section{Conclusion}

Adolescence is a key developmental period in the life course as much of the foundation for the future is established here. Positive Youth Development and the developmental asset model have proven to be an important framework in understanding the skills, opportunities and resources that are needed to protect against youth risk behaviors. Much research has been done with American samples, and it is therefore of great interest to conduct similar studies outside the United States, such as our Norwegian study, in order to investigate whether the link between developmental assets and risk behaviors also exists in other contexts. Such studies can contribute significantly to initiatives and intervention programs that target youth risk behaviors.

The present study confirms the protective role of the developmental assets, although not for all asset categories in multivariate analysis. Moreover, assets categories, such as constructive use of time, did not appear to reliably capture the creative activities that Norwegian youth are involved in. Thus, despite the positive findings and the implications for intervention, more research needs to be done not only to replicate the positive findings but also to ascertain the short- and long-term protective effects of the developmental assets. Risk behaviors have both personal and societal consequences and can cost society dearly if left unaddressed. It can therefore be important to focus on healthy and positive development so that young people will not only avoid problems, but they can also engage in behaviors that will promote their health and development as well as youth's societal participation. In that sense, future research also needs to investigate the developmental assets' ability to promote positive youth outcomes in Norway and other Scandinavian contexts. 


\section{REFERENCES}

Bakken, A. (2018). Ung i Oslo (NOVA Report 6/18). Oslo: NOVA. Retrieved fra http://www.hioa.no/Om-OsloMet/Senter-for-velferdsog-arbeidslivsforskning/NOVA/Publikasjonar/Rapporter/2018/Ung-iOslo-2018.

Bakken, A. (2019). Ungdata. Nasjonale resultater 2019 (NOVA Report 9/19). Oslo: NOVA.

Retrieved from https://fagarkivet.oslomet.no/en/item/asset/dspace:15946/ Ungdata-2019-Nettversjon.pdf.

Balocchini, E., Chiamenti, G., \& Lamborghini, A. (2013). Adolescents: Which risks for their life and health? Journal of Preventive Medicine and Hygiene, 54(4), 191-194.

Benson, P. L. (1990). The troubled journey: A portrait of 6th-12th grade youth. Minneapolis: Search Institute.

Benson, P. L. (2007). Developmental assets: An overview of theory, research, and practice. In R. Silbereisen \& R. Lerner (Eds.), Approaches to positive youth development (pp. 33-59). London: SAGE Publications Ltd.

Boričić, K., Simić, S., \& Erić, J.M. (2015). Demographic and socio-economic factors associated with multiple health risk behaviours among adolescents in Serbia: A cross sectional study. BMC Public Health 15, 157. https://doi. org/10.1186/s12889-015-1509-8.

Chatterjee, D., McMorris, B., Gower, A. L., Forster, M., Borowsky, I. W., \& Eisenberg, M. E. (2018). Adverse childhood experiences and early initiation of marijuana and alcohol use: The potential moderating effects of internal assets. Substance Use \& Misuse, 53(10), 1624-1632.

Cohen, J. (1988). Statistical power analysis for the behavioral sciences (2th ed.). Hillsdale, NJ: Lawrence Erlbaum Associates.

Donovan, J. E., \& Jessor, R. (1985). Structure of problem behavior in adolescence and young adulthood. Journal of Consulting and Clinical Psychology, 53(6), 890-904.

Elias, M. J., \& Weissberg, R. P. (2000). Primary prevention: Educational approaches to enhance social and emotional learning. The Journal of school health, 70(5), 186-190.

Fosco, G. M., Stormshak, E. A., Dishion, T. J., \& Winter, C. E. (2012). Family relationships and parental monitoring during middle school as predictors of early adolescent problem behavior. Journal of Clinical Child \& Adolescent Psychology, 41(2), 202-213. 
Gottfredson, D. C., Gerstenblith, S. A., Soulé, D. A., Womer, S. C., \& Lu, S. (2004). Do after school programs reduce delinquency? Prevention Science, 5(4), 253-266.

Greene, K. M., Eitle, D., \& Eitle, T. M. (2018). Developmental assets and risky sexual behaviors among American Indian youth. Journal of Early Adolescence, 38(1) 50-73.

Leffert, N., Benson, P. L., Scales, P. C., Sharma, A. R., Drak, D. R., \& Blyth, D. A. (1998). Developmental assets: Measurement and prediction of risk behaviors among adolescents. Applied Developmental Science, 2(4), 209-230.

Lerner, R. M., Lerner, J. V., Almerigi, J. B., Theokas, C., Phelps, E., Gestsdottir, S., ... von Eye, A. (2005). Positive youth development, participation in community youth development programs, and community contributions of fifth-grade adolescents: Findings from the first wave of the 4-H Study of Positive Youth Development. The Journal of Early Adolescence, 25, 17-71.

Moradi, P., Fathali Lavasani, F., \& Dejman, M. (2019). Adolescent substance abuse and family environment: A qualitative study. International Journal of High Risk Behaviors and Addiction, 8(2): e83781. doi:10.5812/ijhrba.83781.

Muchimba, M. (2019). Social-ecological predictors of sexual risk behavior among young adults. Journal of Social, Behavioral, and Health Sciences, 13(1), 1-14.

Murphey, D. A., Lamonda, K. H., Carney, J. K., \& Duncan, P. (2004). Relationships of a brief measure of youth assets to health-promoting and risk behaviors. Journal of Adolescent Health, 34, 184-191.

Nordlund, S., \& Østhus, S. (2012). What is alcohol abuse? Attitudes to drinking in seven European countries. Addiction Reasearch \& Theory, 21(5), 402-409.

Overton, W. F. (2010). Life-span development: Concepts and issues. I W. F. Overton \& R. M. Lerner (Red.), The handbook of life-span development (bd. 1, s. 1-29). Hoboken, NJ: John Wiley \& Sons.

Scales, P. C. (1999). Reducing risks and building developmental assets: Essential actions for promoting adolescent health. The Journal of School Health, 69(3), 113-119.

Scales, P. C. (2011). Youth developmental assets in global perspective: Results from international adaptations of the developmental assets profile. Child Indicators Research, 4, 619-645.

Scales, P. C., Benson, P. L., Leffert, N., \& Blyth, D. A. (2000). Contribution of developmental assets to the prediction of thriving among adolescents. Applied Developmental Science, 4, 27-46.

Scales, P. C., Roehlkepartain, E. C., \& Shramko, M. (2017). Aligning youth development theory, measurement, and practice across cultures and contexts: 
Lessons from use of the Developmental Assets Profile. Child Indicators Research, 10, 1145-1178.

Search Institute. (2020). The Developmental Assets ${ }^{\oplus}$ Framework. Retrieved from http://www.search-institute.org.

Shek, D. T. L., Zhu, X., Dou, D., \& Chai, W. (2020). Influence of family factors on substance use in early adolescents: A longitudinal study in Hong Kong, Journal of Psychoactive Drugs, 52(1), 66-76.

Silbereisen, R. K. \& Lerner, R. M. (2007). Approaches to positive youth development: A view of the issues. In R. Silbereisen \& R. Lerner (Eds.), Approaches to positive youth development (pp. 3-30). London: SAGE Publications Ltd.

Spano, S. (2004). Stages of adolescent development. Research facts and findings. Retrieved from http://www.actforyouth.net/resources/rf/rf_stages_0504.pdf.

Spruit, A., van Vugt, E., van der Put, C. \& van der Stouwe, T. (2016). Sports participation and juvenile delinquency: A meta-analytic review. Journal of Youth and Adolescence, 45(4), 655-671.

Straffeloven. (2019). Lov om straff (LOV-2005-05-20-28) Retrieved from https://lovdata.no/dokument/NL/lov/2005-05-20-28?q=straffeloven.

Vatcheva, K. P., Kee, M., McCormick, J. B., \& Rahbar, M. H. (2016). Multicollinearity in regression analyses conducted in epidemiologic studies. Epidemiology, 6(2), 227. https://doi.org/10.4172/2161-1165.1000227.

Wiium, N., \& Dimitrova, R. (2019). Positive youth development across cultures: Introduction to the special issue. Child \& Youth Care Forum, 48, 147-153.

Wiium, N., Dost-Gözkan, A., \& Kosic, M. (2018). Developmental assets among young people in three European contexts. Child \& Youth Care Forum, 48, 187-206.

Wiium, N., \& Wold, B. (2009). An ecological system approach to adolescent smoking behaviour. Journal of Youth and Adolescence, 38, 1351-1363.

Wiium, N., \& Wold, B. (2011). Actions taken by schools when tobacco policies are violated: Associations with adolescent smoking prevalence. Scandinavian Journal of Psychology, 52, 494-501. 
